\title{
Soluble Adhesion Molecules in Preclinical Type 1 Diabetes
}

\author{
ANNA TOIVONEN, PETRI KULMALA, KAISA SAVOLA, HANS K. ÅKERBLOM, \\ MIKAEL KNIP, AND THE CHILDHOOD DIABETES IN FINLAND STUDY GROUP \\ Medical School, University of Tampere, and the Department of Pediatrics, Tampere University Hospital, \\ FIN-33014 Tampere, Finland [A.T., M.K.]; Department of Pediatrics, University of Oulu, FIN-90220 \\ Oulu, Finland [P.K., K.S.]; and Hospital for Children and Adolescents, University of Helsinki, FIN-00290 \\ Helsinki, Finland [H.K.A., M.K.]
}

ABSTRACT

\begin{abstract}
We measured the concentrations of the soluble forms of the intercellular adhesion molecule-1 (sICAM-1) and L-selectin in 95 autoantibody-positive siblings of children with type 1 diabetes and 95 sex- and age-matched siblings testing negative for diabetes-associated autoantibodies to assess the possible role of soluble adhesion molecules as markers of progressive $\beta$-cell destruction in preclinical diabetes and their ability to discriminate between those siblings who progress to clinical disease and those who remain nondiabetic. We observed an inverse correlation between age and the levels of both SICAM-1 ( $r=-0.31, p$ $<0.001)$ and SL-selectin $(r=-0.27, p<0.001)$ in the control siblings but no association with HLA-DR phenotypes. There was no difference in the circulating levels of soluble adhesion molecules between the antibody-positive and negative siblings. Among the antibody-positive siblings, those with at least three autoantibodies had higher sICAM-1 levels $(p<0.01)$ than those testing positive for only one, and siblings with three autoantibodies or more had higher concentrations of SL-selectin $(p<$ $0.01)$ than those with two autoantibodies. Siblings with an islet cell antibody level of 20 Juvenile Diabetes Foundation units or more had higher sICAM-1 concentrations than those with a level below $20(p<0.001)$, and those testing positive for antibodies to the protein tyrosine phosphatase-related IA-2 antigen had increased levels of both sICAM-1 $(p=0.03)$ and sL-selectin ( $p=$ 0.02 ) compared with siblings who tested negative. The antibodypositive siblings who progressed to clinical type 1 diabetes were
\end{abstract}

significantly younger than the nonprogressors $(p<0.001)$ and had higher levels of sICAM-1 initially $(p<0.001)$. The difference in SICAM- 1 concentrations remained significant $(p=0.03)$ after age adjustment. Our results indicate that concentrations of soluble adhesion molecules are increased in the autoantibodypositive siblings who have the highest risk of developing clinical diabetes, suggesting that $\beta$-cell destruction is reflected in increased circulating levels of these molecules. This is supported by the observation of elevated SICAM-1 concentrations in the 29 siblings who actually progressed to clinical type 1 diabetes. Peripheral levels of soluble adhesion molecules are not able to discriminate between progressors and nonprogressors, however, due to substantial overlapping between these two groups. (Pediatr Res 49: 24-29, 2001)

$\quad$ Abbreviations
FPIR, first-phase insulin response
GADA, antibodies to the 65-kD isoform of glutamic acid
decarboxylase
IAA, insulin autoantibodies
IA-2A, antibodies to the protein tyrosine phosphatase-related
IA-2 antigen
ICA, islet cell antibodies
ICAM-1, intercellular adhesion molecule-1
IVGTT, i.v. glucose tolerance test
JDF, Juvenile Diabetes Foundation

Type 1 diabetes is an organ-specific autoimmune disease with a subclinical prodrome characterized by destruction of the insulin-producing $\beta$ cells in the pancreatic islets of Langer-

Received November 25, 1999; accepted March 16, 2000

Correspondence and reprint requests: Mikael Knip, M.D., Hospital for Children and Adolescents, University of Helsinki, P.O. Box 281, FIN-00029 HUCH, Finland.

Supported by grants from the Medical Research Fund, Tampere University Hospital, the Juvenile Diabetes Foundation International (grant 197032), the Novo Nordisk Foundation, and the Alma and K.A. Snellman Foundation, Oulu, Finland.

The Childhood Diabetes in Finland project has been supported by grants from the National Institutes of Health (grant DK-37957), the Sigrid Jusélius Foundation, the Association of Finnish Life Insurance Companies, University of Helsinki, and Novo Nordisk A/S, Bagsvaerd, Denmark. hans. During the pathogenetic process, the islets become infiltrated by inflammatory mononuclear cells, mainly lymphocytes (1) but also macrophages (2), giving the histopathologic lesion characteristic of insulitis. The migration of autoreactive lymphocytes and other leukocytes from the bloodstream into the target organ is a key feature in the etiology of many organspecific autoimmune/inflammatory disorders such as type 1 diabetes. This migration is controlled by selective expression and functional regulation of cell adhesion molecules on the surface of lymphocytes and vascular endothelial cells $(3,4)$. Expression of adhesion molecules is cytokine-dependent, and at least tumor necrosis factor- $\alpha(\mathrm{TNF}-\alpha), \gamma$-interferon, and 
IL-10 have been shown to stimulate their expression $(5,6)$. These cytokines are also essential for the development of insulitis (7-10).

ICAM- 1 is the best-characterized cell surface adhesion molecule. It has five Ig-like domains and belongs to the immunoglobulin superfamily. ICAM-1 expression on vascular endothelial cells has been shown to be increased in the pancreas of patients with newly diagnosed type 1 diabetes (11). Moreover, studies in vitro have demonstrated that induction of ICAM-1 on endothelial cells and interaction with its counter receptor, lymphocyte function-associated antigen-1, are critically involved in antigen-specific $T$ cell activation $(12,13)$. It has also been suggested that ICAM- 1 accelerates the $\beta$-cell destruction driven by cytotoxic T cells (14). L-Selectin is a member of the selectin family characterized by an amino-terminal carbohydrate-binding lectin domain. L-Selectin, expressed on essentially all monocytes, on all naive $\mathrm{T}$ and $\mathrm{B}$ cells, and on a subset of natural killer (NK) cells, acts as a mediator in the initial and transient attachment or rolling of lymphocytes on vascular endothelial cells $(15,16)$.

Soluble forms of ICAM-1 (sICAM-1) and L-selectin (SLselectin) are detectable in the peripheral circulation and have been reported to be increased in various inflammatory disorders including type 1 diabetes (17-19). Additionally, there is evidence from both in vitro and in vivo studies that these adhesion molecules may have an immunoprotective function when in soluble form $(20,21)$.

A proportion of healthy family members of patients with type 1 diabetes share a number of immunologic abnormalities with their affected relatives. Positivity for multiple diseaseassociated autoantibodies increases substantially the risk of progression to clinical diabetes in first-degree relatives, and the risk is further enhanced by an impaired early insulin response to i.v. glucose (22-24). The present study is aimed at comparing the levels of soluble ICAM-1 and L-selectin in unaffected siblings of diabetic children in relation to HLA-defined genetic risk, autoantibody status, and insulin secretory capacity and at assessing whether these soluble adhesion molecules could be used to estimate the risk of future type 1 diabetes in siblings of affected children.

\section{METHODS}

Subjects. The population was derived from the nationwide Childhood Diabetes in Finland (DiMe) study (25). From September 1986 to April 1989, 801 index cases aged less than $15 \mathrm{y}$ with newly diagnosed type 1 diabetes and their families were invited to take part in the study aimed at evaluating the role of genetic, environmental, and immunologic factors in the development of type 1 diabetes. The study protocol had been approved by the ethical committees of all 31 participating hospitals, and informed consent was obtained from the subjects and/or their parents. The 801 families contained altogether 977 initially unaffected siblings under the age of $20 \mathrm{y}$, and sequential blood samples were taken from these siblings for the analysis of diabetes-associated autoantibodies. The first blood sample for each sibling was obtained at or close to the diagnosis of the index case, and subsequent samples were taken at intervals of 3-6 mo over the first $2 y$ and thereafter at intervals of $12 \mathrm{mo}$ for up to $4 \mathrm{y}$. The siblings were observed to the end of December 1997 unless type 1 diabetes was diagnosed before that date. Diagnosis was based on clinical symptoms and an increased random blood glucose concentration $(>10 \mathrm{mmol} / \mathrm{L})$, or elevated fasting blood glucose $(>6.7 \mathrm{mmol} / \mathrm{L})$, or random blood glucose $>10 \mathrm{mmol} / \mathrm{L}$ on two occasions in the absence of symptoms. There were 755 siblings with at least one blood sample available $(77.3 \%)$. The first sample for each of the siblings was analyzed for ICA, IAA, GADA, and IA-2A. The population of this case-control study included all 95 siblings whose initial sample was positive for at least one autoantibody specificity out of the four analyzed. The control group comprised 95 sex- and age-matched ( $\pm 6 \mathrm{mo}$ ) siblings who remained antibody-negative throughout the follow-up. The mean age of the cases was $9.78 \mathrm{y}$ (range, 1.1-18.9) and that of the controls 9.79 y (range, 1.4-18.6). The levels of sICAM-1 and SL-selectin were measured in the first blood sample available, and these samples were stored at $-20^{\circ} \mathrm{C}$ or lower temperature until analysis. Twenty-nine autoantibody-positive siblings had progressed to clinical type 1 diabetes by the end of 1997 .

Soluble adhesion molecule assays. SICAM-1 and SL-selectin concentrations were analyzed with specific ELISA kits (Bender Medsystems Diagnostics GmbH, Vienna, Austria). The assays are based on two MAb directed against different epitopes on the soluble adhesion molecules. Diluted serum samples $(1: 10$ for sICAM-1 and 1:200 for SL-selectin) were added as duplicates to the microtiter wells, which were precoated with murine MAb to human ICAM-1or L-selectin. A second horseradish peroxidase-conjugated murine MAb was then added to bind a second epitope on the molecule captured by the first antibody, and the plates were incubated at room temperature for $1 \mathrm{~h}$ in the ICAM-1 assay and for $2 \mathrm{~h}$ in the L-selectin assay. After thorough washing to remove the unreactive component, 3,3,5,5-tetramethylbenzidine was added to the wells to form a colored end product, and the plates were incubated for an additional $15 \mathrm{~min}$. The process was stopped by adding phosphoric acid, and the absorbances were measured at a wavelength of $450 \mathrm{~nm}$ with a Multiscan MS photometer (Labsystems, Helsinki, Finland). The results were read from a standard curve and expressed as $\mu \mathrm{g} / \mathrm{L}$. The coefficient of intraassay variation in the sICAM-1 assay was less than $5 \%$ and that of interassay variation less than $8 \%$, the corresponding figures for the sL-selectin assay being less than 4 and $5 \%$, respectively.

Autoantibody assays. ICA levels were determined by a standard immunofluorescence method using sections of frozen human group 0 pancreas (26). All sera with detectable ICA were titrated to end-point dilution, and the results were expressed in JDF units. The detection limit was 2.5 JDF units. Our laboratory has participated in the international workshops on the standardization of the ICA assay in which our sensitivity was $100 \%$, specificity $98 \%$, validity $98 \%$, and consistency $98 \%$ in the most recent round.

IAA levels were quantified with a radio-binding assay modified from that described by Palmer et al. (27). Endogenous insulin was removed with acid charcoal before the analysis. Free and bound insulin was separated after incubation with mono- ${ }^{125} \mathrm{I}\left(\mathrm{Tyr}^{\mathrm{A} 14}\right)$ human insulin (Novo Research Institute, 
Bagsvaerd, Denmark) for $20 \mathrm{~h}$ in the absence or presence of an excess of unlabeled insulin. IAA levels were expressed as $\mathrm{nU} / \mathrm{mL}$, where $1 \mathrm{nU} / \mathrm{mL}$ corresponds to a specific binding of $0.01 \%$ of the total counts. The interassay coefficient of variation was less than $8 \%$. A subject was considered positive for IAA when specific binding exceeded $54 \mathrm{nU} / \mathrm{mL}$ (99th percentile in 105 nondiabetic subjects). The disease sensitivity of our IAA assay was $26 \%$, and the specificity was $97 \%$, based on 140 samples derived from the 1995 Multiple Autoantibody Workshop (28).

GADA and IA-2A antibodies were analyzed with a radiobinding assay described in detail elsewhere (29-31). Briefly, recombinant cDNA encoding human islet GAD65 or the intracellular part of the IA-2 molecule was transcribed and translated according to the manufacturer's instructions (Promega, Madison, WI, U.S.A.). Serum samples were incubated overnight with ${ }^{35} S$-methionine-labeled GAD65 or IA-2. On the next day, protein A sepharose (Pharmacia, Uppsala, Sweden) diluted with Tris-buffered saline with Tween was added to isolate the immune complexes. After incubation on a shaker, the samples were washed with Tris-buffered saline with Tween, after which their activity was measured in a liquid scintillation counter. All samples were analyzed in duplicate. The results were expressed in relative units (RU) either linked to a strongly positive standard (GADA) or based on a standard curve run on each plate (IA-2A). The cutoff for antibody positivity (99th percentile in more than 370 nondiabetic children and adolescents) was 6.6 RU for GADA and $0.43 \mathrm{RU}$ for IA-2A. The disease sensitivity of the GADA assay was $79 \%$ and the specificity $97 \%$ based on the 1995 Multiple Autoantibody Workshop (28). The corresponding characteristics of the IA-2A assay were 62 and $97 \%$ based on 140 samples derived from the Multiple Autoantibody Workshop (28).

IVGTT. IVGTT were performed after a preceding fast of $10-16 \mathrm{~h}$ by infusing $0.5 \mathrm{~g}$ glucose per kilogram body weight in a $20 \%$ solution i.v. over a period of $3 \mathrm{~min} \pm 15 \mathrm{~s}$. Blood samples were taken before the infusion ( $0 \mathrm{~min})$ and $1,3,6,10$, 20, 30, 40, 50, and $60 \mathrm{~min}$ after its completion. Serum insulin concentrations were measured by RIA (32). The FPIR to glucose was defined as the sum of the 1- and 3-min serum insulin concentrations. FPIR levels $<45 \mathrm{mU} / \mathrm{L}$, which correspond to the third percentile of FPIR values measured in healthy control subjects (33), were considered abnormally low. This limit was defined after correction for assay differences on the basis of an insulin standardization round within the ICA Register User Study. Blood glucose levels were quantified by the glucose oxidase method (34). The glucose disappearance rate $\left(\mathrm{K}_{\mathrm{g}}\right)$ was calculated to evaluate the degree of glucose tolerance and was expressed as the percentage decrease in blood glucose per minute. A $\mathrm{K}_{\mathrm{g}}<1.30 \% /$ min was considered abnormal.

$\boldsymbol{H L A} \boldsymbol{A} \boldsymbol{D R}$ alleles. HLA-DR alleles were typed using conventional HLA serology as described by Tuomilehto-Wolf et al. (35).

Statistical analyses. The data were analyzed by linear regression, ANOVA, and $t$ test. Analysis of covariance was used to adjust for the effect of age on the circulating concentrations of soluble adhesion molecules. Based on the assumption of a mean sICAM-1 level of $250 \mu \mathrm{g} / \mathrm{L}$ and an SD of $75 \mu \mathrm{g} / \mathrm{L}$ in siblings of children with type 1 diabetes, the present study design provided the possibility to detect a $17 \%$ difference in mean sICAM concentrations between the two groups studied at a statistical power of $80 \%$.

\section{RESULTS}

The autoantibody-positive siblings had a mean serum sICAM-1 concentration of 277 (74; SD) $\mu \mathrm{g} / \mathrm{L}$, which was similar to that seen in antibody-negative siblings [279 (78) $\mu \mathrm{g} / \mathrm{L}]$; nor was there any significant difference in serum SLselectin levels between the two groups [2750 (940) $\mu \mathrm{g} / \mathrm{L}$ versus $2720(830) \mu \mathrm{g} / \mathrm{L}]$. The boys and girls had comparable concentrations of sICAM-1 and SL-selectin among the autoantibody-negative siblings (data not shown). An inverse association existed between age and both the sICAM-1 levels $(r=$ $-0.31, p<0.001)$ and sL-selectin concentrations $(r=-0.27$, $p<0.001)$ in the control siblings, and the sICAM-1 and SL-selectin concentrations were correlated $(r=0.46, p<$ 0.001 ). No relationship was observed between sICAM-1 and SL-selectin levels and the degree of HLA identity with the proband (data not shown) or various HLA-DR phenotypes (Fig. 1) among the antibody-negative children.

Among the autoantibody-positive siblings, subjects with high ICA levels ( $\geq 20$ JDF $U$ ) had higher serum sICAM-1 concentrations than those with low ICA levels, even after adjustment for age [314 (82) $\mu \mathrm{g} / \mathrm{L}$ versus 254 (59) $\mu \mathrm{g} / \mathrm{L}, p<$ $0.001]$, whereas the SL-selectin concentrations were of the same magnitude in these two groups. Siblings testing positive for IA-2A had higher SL-selectin and sICAM-1 concentrations than those without detectable IA-2A [sL-selectin $3010(1020) \mu \mathrm{g} / \mathrm{L}$ versus 2570 (830) $\mu \mathrm{g} / \mathrm{L}, p=0.02$; and sICAM-1 296 (77) $\mu \mathrm{g} / \mathrm{L}$ versus 263 (70) $\mu \mathrm{g} / \mathrm{L}, p=0.03]$. There were no significant differences in circulating concentrations of soluble adhesion molecules between the siblings testing positive for GADA or IAA and those who were negative for them. Siblings testing positive for two or more antibodies had significantly higher sICAM-1 levels than those with only one detectable autoantibody specificity or none at all $[297$ (83) $\mu \mathrm{g} / \mathrm{L}$ versus 272 (72) $\mu \mathrm{g} / \mathrm{L}, p<0.05]$. A more detailed analysis showed increased sICAM-1 concentrations ( $p=0.006$ ), particularly in those with three or four antibodies, relative to those testing positive for only one antibody (Fig. 2A). Siblings with three or four autoantibodies had higher sL-selectin concentrations than those testing positive for two antibodies $(p=0.005$; Fig. $2 B)$. There were no significant differences in the circulating concentrations of sICAM-1 and sL-selectin between the siblings with a reduced FPIR in their first IVGTT and those with a normal FPIR (data not shown).

Those siblings who later progressed to clinical type 1 diabetes had higher sICAM-1 levels than the nonprogressors [313 (66) $\mu \mathrm{g} / \mathrm{L}$ versus 260 (72) $\mu \mathrm{g} / \mathrm{L}, p<0.001]$. This difference remained significant $(p=0.03)$ after adjustment for age. With a cutoff level of $332 \mu \mathrm{g} / \mathrm{L}$ (mean +1 SD in the nonprogressors), an elevated sICAM-1 concentration had a sensitivity of $38 \%$, a specificity of $83 \%$, and a positive predictive value of $52 \%$ for type 1 diabetes. Correspondingly, with a cutoff level 

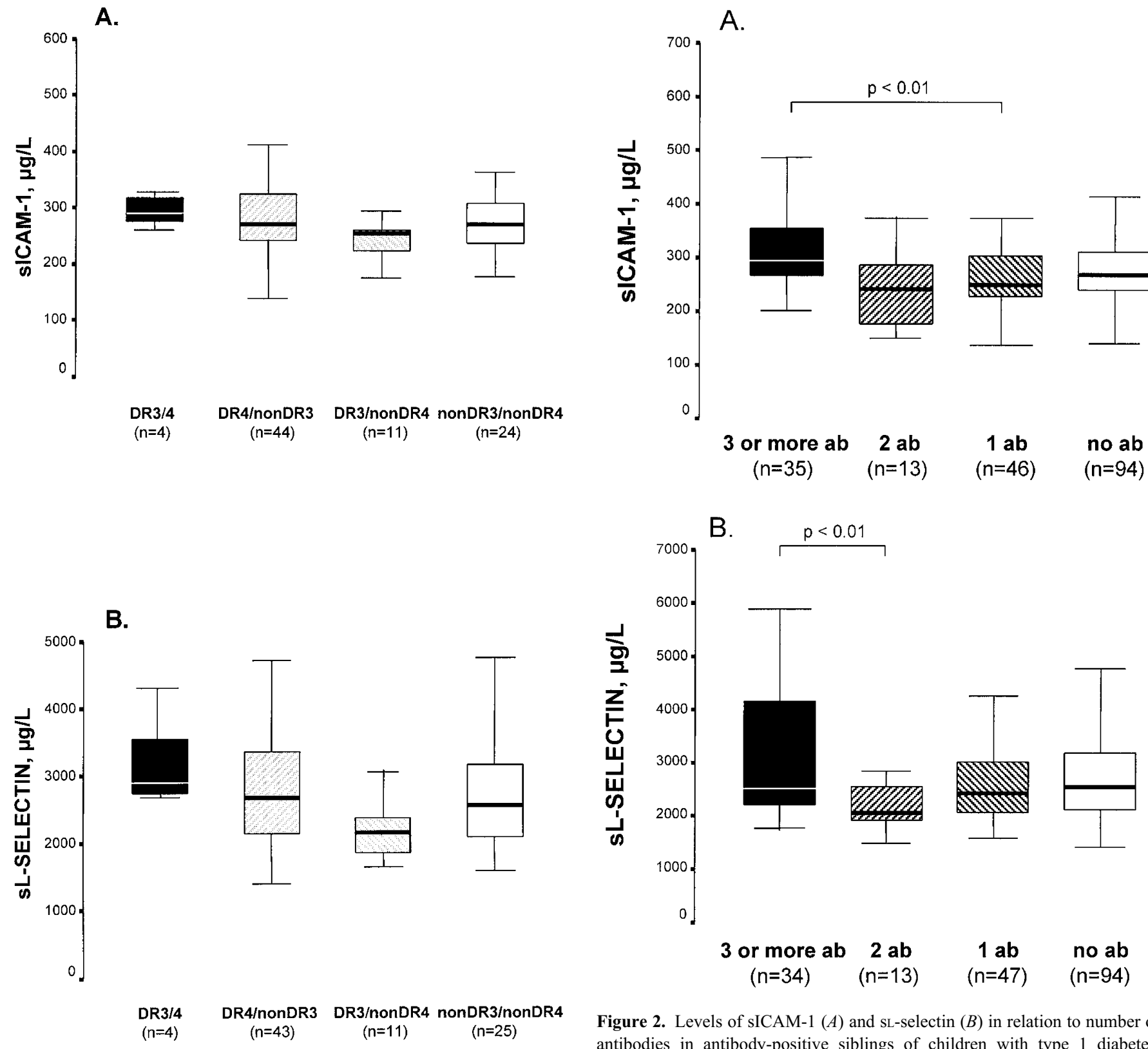

Figure 1. Levels of sICAM-1 $(A)$ and SL-selectin $(B)$ in antibody-negative siblings by HLA-DR status. One-way ANOVA: $\mathrm{F}_{\mathrm{df}}=3=1.24, p=0.30$ for sICAM-1 and $\mathrm{F}_{\mathrm{df}=3}=2.25, p=0.09$ for sL-selectin.

of $404 \mu \mathrm{g} / \mathrm{L}$ (mean $+2 \mathrm{SD}$ in the nonprogressors), the disease sensitivity was $10 \%$, the specificity $95 \%$, and the positive predictive value $50 \%$. No significant difference in sL-selectin concentrations was seen between the progressors and nonprogressors [2878 (879) $\mu \mathrm{g} / \mathrm{L}$ versus 2697 (960) $\mu \mathrm{g} / \mathrm{L}, p=0.40]$.

\section{DISCUSSION}

Elevated levels of sICAM-1 and SL-selectin have been reported in patients with type 1 diabetes and in subjects at risk for type 1 diabetes, and this has been interpreted as reflecting an active immune process resulting in increased release of soluble adhesion molecules (17). In the present study, we observed higher sICAM-1 levels in siblings with three or four autoantibodies than in those with one antibody, and also higher con-

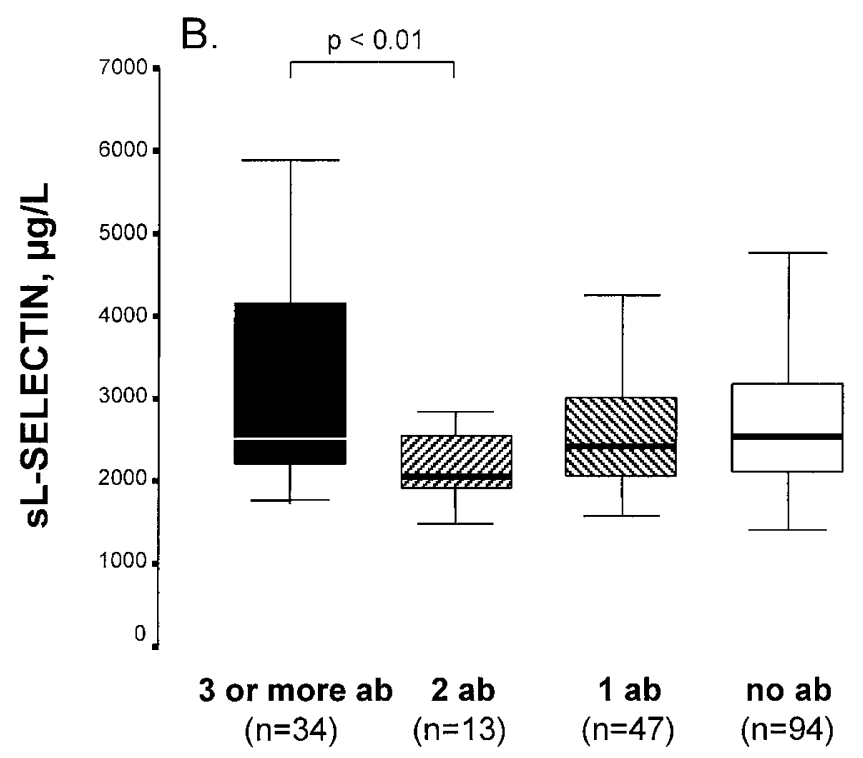

Figure 2. Levels of sICAM-1 $(A)$ and sL-selectin $(B)$ in relation to number of antibodies in antibody-positive siblings of children with type 1 diabetes. One-way ANOVA: $\mathrm{F}_{\mathrm{df}=3}=4.18, p=0.007$ for sICAM- 1 and $\mathrm{F}_{\mathrm{df}=3}=4.05$, $p=0.008$ for sL-selectin. $A b$ indicates antibodies.

centrations of SL-selectin in siblings with three or four antibodies than in those with two antibodies. Positivity for three or more antibodies could reflect an ongoing destructive immune process in pancreatic islets, because the combination of three or four autoantibodies has been reported in a series of family studies to have a substantially higher predictive value for type 1 diabetes than positivity for a single antibody $(22,24,36)$.

Whereas the normal concentrations of circulating soluble adhesion molecules are extensively reported in healthy adults $(17,37,38)$ and available from the manufacturers of commercial kits, reference ranges for children have not been established. One has also to remember that absolute values are not comparable between various studies on soluble adhesion molecules, because different reagents may result in variable concentrations due to differences in antibody specificity and in 
standards used. So far, no international workshop has been arranged to compare different assays for soluble adhesion molecules. Our study confirms the earlier finding that levels of soluble adhesion molecules are higher in young children than in older children and adults (39-41), as we observed an inverse correlation between age and both SICAM-1 and SLselectin concentrations. This emphasizes the need to use agematched controls in all analyses of the possible clinical impact of circulating concentrations of soluble adhesion molecules. In the present survey, the cases and controls were carefully matched for age, which has not been the case in previous reports on the possible role of soluble adhesion molecules in type 1 diabetes $(17,20)$.

We also observed substantial interindividual variations in the circulating levels of both soluble adhesion molecules, suggesting that there is a multitude of endogenous and exogenous factors affecting sICAM- 1 and SL-selectin concentrations in the peripheral circulation. In contrast with earlier reports $(17,41)$, we observed a significant correlation between circulating sICAM-1 and SL-selectin levels, whereas there was no difference in the concentrations of soluble adhesion molecules between the boys and the girls.

There was a trend for lower sICAM-1 and sL-selectin concentrations in antibody-negative siblings with the HLA-DR3/ non-DR4 phenotype than in those who were heterozygous for HLA-DR3/4 or carried the DR4/non-DR3 or non-DR3/nonDR4 combinations, but the difference remained nonsignificant for both adhesion molecules. This suggests that HLA genes do not play a crucial role in regulating the circulating levels of soluble adhesion molecules.

The siblings with an ICA level of 20 JDF U or more had higher sICAM-1 concentrations than those with a lower ICA titer. An ICA level of $20 \mathrm{JDF} \mathrm{U}$ or more has previously been found to be highly predictive of progression to clinical disease in first-degree relatives of children with type 1 diabetes (42). We also observed higher sICAM-1 and SL-selectin concentrations in the siblings who tested positive for IA-2A than in the IA-2A-negative ones. IA-2A have been reported to appear relatively late in the prediabetic phase and to reflect a high risk of progression to clinical disease $(42,43)$.

The early insulin response to i.v. glucose has been used as an indirect measure of the remaining $\beta$-cell mass, and the FPIR has been shown to decrease along with progression to clinical type 1 diabetes $(33,36)$. We could not find any difference in the levels of soluble adhesion molecules between the autoantibody-positive siblings with a reduced FPIR and those with a normal FPIR.

Our observations show that the siblings with the highest risk of manifesting clinical type 1 diabetes, i.e. those with three or four diabetes-associated autoantibodies, have increased concentrations of sICAM-1 and SL-selectin in their peripheral circulation. In addition, the antibody-positive siblings who progressed to clinical diabetes during prospective observation had higher initial levels of sICAM-1 than those who remained nondiabetic. There was a substantial overlapping in the circulating levels of soluble adhesion molecules between the progressors and nonprogressors, however, implying that crosssectional peripheral sICAM-1 levels can hardly provide a clinically meaningful tool for identifying those children who will present with clinical type 1 diabetes. We suggest that levels of soluble adhesion molecules reflect nonspecific generalized endothelial or mononuclear cell activation rather than a specific pathophysiologic mechanism in the pathogenesis of type 1 diabetes. The initially increased concentrations of circulating sICAM-1 in those who later progressed to clinical diabetes may alternatively reflect defensive mechanisms against progressive $\beta$-cell destruction, because there are indications that sICAM-1 may play a protective role $(20,21)$. This cross-sectional case-control study cannot rule out the possibility that soluble adhesion molecules may be of predictive value in preclinical type 1 diabetes. This issue should be addressed by means of longitudinal follow-up studies of subjects with an increased risk of progression to type 1 diabetes.

Acknowledgments. The authors thank Susanna Heikkilä, Sirpa Anttila, Riitta Päkkilä, and Päivi Koramo for their skillful technical assistance.

The Childhood Diabetes in Finland (DiMe) Study Group has the following members: principal investigators, H.K. Åkerblom and J. Tuomilehto; coordinators, R. Lounamaa and L. Toivonen; data management, E. Virtala and J. Pitkäniemi. Local investigators are A. Fagerlund, M. Flittner, B. Gustafsson, C. Häggquist, A. Hakulinen, L. Herva, P. Hiltunen, T. Huhtamäki, N.-P. Huttunen, T. Huupponen, T. Joki, R. Jokisalo, M.-L. Käär, S. Kallio, E.A. Kaprio, U. Kaski, M. Knip, L. Laine, J. Lappalainen, J. Mäenpää, A.-L. Mäkelä, K. Niemi, A. Niiranen, A. Nuuja, P. Ojajärvi, T. Otonkoski, K. Pihlajamäki, S. Pöntynen, J. Rajantie, J. Sankala, J. Schumacher, M. Sillanpää, M.-R. Ståhlberg, C.-H. Stråhlmann, T. Uotila, M. Väre, P. Varimo, and G. Wetterstrand. Special investigators are A. Aro, M. Hiltunen, H. Hurme, H. Hyöty, J. Ilonen, J. Karjalainen, M. Knip, P. Leinikki, A. Miettinen, T. Petäys, L. Räsänen, H. Reijonen, A. Reunanen, T. Saukkonen, E. Savilahti, E. Tuomilehto-Wolf, P. Vähäsalo, and S.M. Virtanen.

\section{REFERENCES}

1. Bottazzo G, Dean B, McNally J, MacKay E, Swift P, Gample D 1985 In situ characterization of autoimmune phenomena and expression of HLA molecules in the pancreas in diabetic insulitis. N Engl J Med 313:353-360

2. Foulis A, McGill M, Farquharson M 1991 Insulitis in type 1 (insulin-dependent) diabetes mellitus in man-macrophages, lymphocytes, and interferon-gammacontaining cells. J Pathol 165:97-103

3. Springer TA 1990 Adhesion receptors of the immune system. Nature 346:425-434

4. Butcher EC 1991 Leukocyte-endothelial cell recognition: three (or more) steps to specificity and diversity. Cell 67:1033-1036

5. Doukas J, Pober JS 1990 IFN-gamma enhances endothelial activation induced by tumor necrosis factor but not IL-1. J Immunol 145:1727-1733

6. Doukas J, Mordes JP 1993 T lymphocytes capable of activating endothelial cells in vitro are present in rats with autoimmune diabetes. J Immunol 150:1036-1046

7. Higuchi Y, Herrera P, Muniesa PHJ, Belin D, Ohashi P, Aichele P, Orci L, Vassalli JD, Vassalli P 1992 Expression of a tumor necrosis factor-alfa transgene in murine pancreatic beta cells results in severe and permanent insulitis without evolution towards diabetes. J Exp Med 176:1719-1731

8. Picarella DE, Kratz A, Li C, Ruddle NH, Flavell RA 1993 Transgenic tumor necrosis factor (TNF)-alfa production in pancreatic islets leads to insulitis, not diabetes. J Immunol 150:4136-4150

9. Yang XD, McDevitt HO 1994 Role of TNF-alfa in the development of autoimmunity and the pathogenesis of insulin-dependent diabetes mellitus in NOD mice. Circ Shock 43:198-201

10. Yang XD, Tisch R, Singer SM, Cao ZA, Liblau R, Schreiber RD, McDevitt HO 1994 Effect of tumor necrosis factor-alfa on insulin-dependent diabetes mellitus in NOD mice. I. The early development of autoimmunity and diabetogenic process. J Exp Med 180:995-1004 
11. Itoh N, Hanafusa T, Miyazaki A, Miyagava JI, Yamagata K, Yamamoto K, Waguri M, Imagava A, Tamura S, Inada M, Kawata S, Tarui S, Kono N, Matsuzava Y 1993 Mononuclear cell infiltration and its relation to the expression of major histocompatibility complex antigens and adhesion molecules in pancreas biopsy specimens from newly diagnosed insulin-dependent diabetes mellitus patients. J Clin Invest 92:23132322

12. Van Seventer GA, Newman W, Schimizu Y, Nutman TB, Tanaka Y, Horgan KJ, Gopal TV, Ennis E, O' Sullivan D, Grey H, Shaw S 1991 Analysis of T cell stimulation by superantigen plus major histocompatibility complex class II molecules or by $\mathrm{CD} 3$ monoclonal antibody: costimulation by purified adhesion ligands VCAM-1, ICAM-1, but not ELAM-1. J Exp Med 174:901-913

13. Damle NK, Klussman K, Linsley PS, Aruffo A 1992 Differential costimulatory effects of adhesion molecules B7, ICAM-1, LFA-3, and VCAM-1 on resting and antigenprimed CD+T lymphocytes. J Immunol 148:1985-1992

14. Yagi N, Yokono K, Amano K, Nagata M, Tsukamoto K, Hasegawa Y, Yoneda R, Okamoto N, Moriyama H, Miki M, Tominaga Y, Miyazaki J, Yagita H, Okumura K, Mizoguchi A, Miki A, Ide C, Maeda S, Kasuga M 1995 Expression of intercellular adhesion molecule 1 on pancreatic beta-cells accelerates beta-cell destruction by cytotoxic T-cells in murine autoimmune diabetes. Diabetes 44:744-752

15. Carlos TM, Harlan JM 1994 Leukocyte-endothelial adhesion molecules. Blood $84: 2068-2101$

16. Springer TA 1994 Traffic signals for lymphocyte recirculation and leukocyte emigration: the multistep paradigm. Cell 76:301-314

17. Lampeter ER, Kishimoto TK, Rothlein R, Mainolfi EA, Bertrams J, Kolb H, Martin S 1992 Elevated levels of circulating adhesion molecules in IDDM patients and in subjects at risk for IDDM. Diabetes 41:1668-1671

18. Oymar K, Bjerknes R 1998 Differential patterns of circulating adhesion molecules in children with bronchial asthma and acute bronchiolitis. Pediatr Allergy Immunol 9:73-79

19. Laucella SA, Gaddi E, Balbaryski J, Giraudi V, Cuttica RJ 1999 Soluble intercellular adhesion molecule-1 in paediatric connective tissue diseases. Acta Paediatr 88:399403

20. Roep BO, Heidenthal E, de Vries RRP, Kolb H, Martin S 1994 Soluble forms of intercellular adhesion molecule-1 in insulin-dependent diabetes mellitus. Lancet 343:1590-1593

21. Martin S, Heidenthal E, Schulte B, Rothe H, Kolb H 1998 Soluble forms of intercellular adhesion molecule-1 inhibit insulitis and onset of autoimmune diabetes. Diabetologia 41:1298-1303

22. Bingley PJ, Christie MR, Bonifacio E, Bonfanti R, Shattock N, Fonte MT, Bottazzo GF, Gale EAM 1994 Combined analysis of autoantibodies improves prediction of IDDM in islet cell autoantibody-positive relatives. Diabetes 43:1304-1310

23. Bingley PJ 1996 Interactions of age, islet cell antibodies, insulin autoantibodies, and first-phase insulin response in predicting risk of progression to IDDM in ICA+ relatives: the ICARUS data set. Islet Cell Antibody Register Users Study. Diabetes 45:1720-1728

24. Kulmala P, Savola K, Petersen JS, Vähäsalo P, Karjalainen J, Löppönen T, Dyrberg T, Åkerblom HK, Knip M 1998 Prediction of insulin-dependent diabetes mellitus in siblings of children with diabetes. A population-based study. The Childhood Diabetes in Finland Study Group. J Clin Invest 101:327-336

25. Tuomilehto J, Lounamaa R, Tuomilehto-Wolf E, Reunanen A, Virtala E, Kaprio EA, Åkerblom HK 1992 Epidemiology of childhood diabetes in Finland: background of a nationwide study of type 1 (insulin-dependent) diabetes mellitus. Childhood Diabetes in Finland Study Group. Diabetologia 35:70-76
26. Bottazzo GF, Florin-Christensen A, Doniach D 1974 Islet-cell antibodies in diabetes mellitus with autoimmune polyendocrine deficiencies. Lancet 2:1279-1282

27. Palmer JP, Asplin CM, Clemons P, Lyen K, Tatpati O, Raghu PK, Paquette TL 1983 Insulin antibodies in insulin-dependent diabetics before insulin treatment. Science 222:1337-1339

28. Verge CF, Stenger D, Bonifacio E, Colman PG, Pilcher C, Bingley PJ, Eisenbarth GS 1998 Combined use of autoantibodies (IA-2 autoantibody, GAD autoantibody, insulin autoantibody, cytoplasmic islet cell antibodies) in type 1 diabetes: Combinatorial Islet Autoantibody Workshop. Diabetes 47:1857-1866

29. Petersen JS, Hejnaes KR, Moody A, Karlsen AE, Marshall MO, Hoier-Madsen M, Boel E, Michelsen BK, Dyrberg T 1994 Detection of GAD65 antibodies in diabetes and other autoimmune diseases using a simple radioligand assay. Diabetes 43:459467

30. Sabbah E, Kulmala P, Veijola R, Vähäsalo P, Karjalainen J, Tuomilehto-Wolf E, Akerblom HK, Knip M 1996 Glutamic acid decarboxylase antibodies in relation to other autoantibodies and genetic risk markers in children with newly diagnosed insulin-dependent diabetes. Childhood Diabetes in Finland Study Group. J Clin Endocrinol Metab 81:2455-2459

31. Savola K, Bonifacio E, Sabbah E, Kulmala P, Vähäsalo P, Karjalainen J, TuomilehtoWolf E, Meriläinen J, Åkerblom HK, Knip M 1998 IA-2 antibodies-a sensitive marker of IDDM with clinical onset in childhood and adolescence. Childhood Diabetes in Finland Study Group. Diabetologia 41:424-429

32. Herbert V, Lau KS, Gottlieb CW, Bleicher SJ 1965 Coated charcoal immunoassay of insulin. J Clin Endocrinol 25:1375-1384

33. Srikanta S, Ganda O, Gleason RE, Jackson RA, Soeldner JS, Eisenbarth GS 1984 Pre-type 1 diabetes: linear loss of beta cell response to intravenous glucose. Diabetes 33:717-720

34. Hjelm M 1966 Enzymatic determination of hexoses in blood and urine. J Clin Lab Invest 192(suppl):85-98

35. Tuomilehto-Wolf E, Tuomilehto J, Cepaitis Z, Lounamaa R 1989 New susceptibility haplotype for type 1 diabetes. Childhood Diabetes in Finland Study Group. Lancet 2:299-302

36. Verge CF, Gianani R, Kawasaki E, Yu L, Pietropaolo M, Jackson RA, Chase HP, Eisenbarth GS 1996 Prediction of type 1 diabetes in first-degree relatives using a combination of insulin, GAD, and ICA512bdc/IA-2 autoantibodies. Diabetes 45:926933

37. Rothlein R, Mainolfi EA, Czajkowski M, Marlin SD 1991 A form of circulating ICAM-1 in human serum. J Immunol 147:3788-3793

38. Gearing AJH, Newman W 1993 Circulating adhesion molecules in disease. Immunol Today 14:506-512

39. Furukawa S, Imai K, Matsubara T, Yone K, Yachi A, Okumara K, Yabuta K 1992 Increased level of circulating intercellular adhesion molecule 1 in Kawasaki disease. Arthritis Rheum 35:672-677

40. Nash MC, Shah V, Dillon MJ 1995 Soluble adhesion molecules and von Willebrand factor in children with Kawasaki disease. Clin Exp Immunol 101:13-17

41. Paronen J, Vaarala O, Savilahti E, Saukkonen T, Åkerblom HK 1996 Soluble adhesion molecules and oral antigen feeding in infants. Pediatr Res 40:276-279

42. Knip M, Karjalainen J, Åkerblom HK 1998 Islet cell antibodies are less predictive of IDDM among unaffected children in general population than in sibs of children with diabetes. Childhood Diabetes in Finland Study Group. Diabetes Care 21:1670-1673

43. Christie MR, Roll U, Payton MA, Hatfield ECI, Ziegler AG 1997 Validity of screening for individuals at risk for type 1 diabetes by combined analysis of antibodies to recombinant proteins. Diabetes Care 20:965-970 